Published in final edited form as:

Cytokine Growth Factor Rev. 2016 June ; 29: 109-115. doi:10.1016/j.cytogfr.2016.02.006.

\title{
Monocyte and interferon based therapy for the treatment of ovarian cancer
}

\author{
Daniel S. Green ${ }^{1,{ }^{*}}$, Ana T. Nunes ${ }^{2}$, Christina M. Annunziata ${ }^{2}$, and Kathryn C. Zoon ${ }^{1}$ \\ ${ }^{1}$ Cytokine Biology Section, National Institute of Allergy and Infectious Diseases, National Institute \\ of Health \\ ${ }^{2}$ Translational Genomics Section, National Cancer Institute, National Institutes of Health
}

\begin{abstract}
Cytokines and cells of the innate immune system have been shown to be critical regulators in the elimination, equilibrium and escape of malignant cells. Despite in vitro and in vivo evidence, components of the innate immune system have shown limited efficacy in the treatment of ovarian cancer. Intraperitoneal immunotherapies are a promising field that has not yet been fully explored in ovarian cancer. Cytokine immunotherapy using interferon alpha (IFN-a) and interferon gamma $(\mathrm{IFN}-\gamma)$ has predominantly been used intraperitoneally in ovarian cancer, with promising results. Early studies also showed that autologous monocytes infused into the peritoneum have anti-tumor properties. Combination therapies have been shown to be more effective in treating cancer than monotherapies. Based on these observations the combination of cell therapy with cytokine therapy may provide a unique strategy for the treatment of chemotherapy resistant solid cancers.
\end{abstract}

\section{Keywords}

Monocyte; Interferon Alpha; Interferon Gamma; Ovarian Cancer; immunotherapy

\section{Introduction}

Ovarian cancer is the number one cause of death due to gynecological malignancies, and the fifth leading cause of death due to cancer in women. Patients present late in the course of disease (Stage 3 or 4 ) as a result of little to no early symptoms and no current non-invasive testing[1]. While surgical debulking and intravenous chemotherapy with intraperitoneal chemotherapy result in an initial remission in disease, approximately $75 \%$ of patients will relapse. The relapse is characterized by chemotherapy refractory disease that ultimately

\footnotetext{
*Address Correspondence to: Daniel S. Green (Daniel.green2@ nih.gov), Cytokine Biology Section, NIAID, NIH, 50 South Drive, RM 5515, Bethesda MD USA, 20892.

Ana T. Nunes (ana.nunes@nih.gov), Medical Oncology Branch, NCI, 10 Center DR, RM 12N226, Bethesda MD USA, 20814

Christina M. Annunziata (ca180n@ nih.gov), Women's Malignancy Branch, NCI, NIH, Translational Genomics Section, 10 Center DR RM 3B43A, Bethesda MD USA, 20892

Kathryn C. Zoon (kz15m@nih.gov), Cytokine Biology Section, NIAID, NIH, 50 South Drive, RM 5515, Bethesda MD USA, 20892

Publisher's Disclaimer: This is a PDF file of an unedited manuscript that has been accepted for publication. As a service to our customers we are providing this early version of the manuscript. The manuscript will undergo copyediting, typesetting, and review of the resulting proof before it is published in its final citable form. Please note that during the production process errors may be discovered which could affect the content, and all legal disclaimers that apply to the journal pertain.
} 
becomes chemotherapy resistant. Currently there are no definitive second line treatments for patients who fail standard of care. Patients with ovarian cancer have a 5-year survival rate of 25-30\%, making it one of the most aggressive malignancies, and the most lethal gynecological malignancy[2].

While surgery and chemotherapy have been the gold standard for ovarian cancer, clinical trials are being conducted to evaluate if immune-based cellular and protein therapies can be effective in recurrent or cisplatin resistant ovarian cancer. Tumor infiltrating lymphocytes (TILS) have been well characterized in ovarian cancer [3,4] and are found both in the solid tumors and ascites $[5]$. Their presence in patients has been associated with an improved prognosis and a delayed recurrence, thought to be due to their tumor specific cytolytic activity $[6,7]$.

T-cell activation depends on a balance of co-stimulatory factors such as CD28, OX40 and CD27 in combination with co-inhibitory molecules including cytotoxic T-lymphocyte associated protein 4 (CTLA-4) and programmed death-1 (PD-1). Expression of programmed cell death 1 ligand 1 and 2 (PD-Ls) on the surface of cancer cells act as co-regulatory signals by binding to PD-1 resulting in host immune evasion, suppressing the TILS [8]. High levels of PDL-1 were found in ovarian cancer in both the solid tumor and ascites and have been shown to promote peritoneal dissemination $\left[{ }^{9}\right]$. By evaluating through immunohistochemistry multiple different tumor tissue types, patients with high levels of PDL-1 expression in their tumor tissue were found to have lower levels of tumor infiltrating CD8+ lymphocytes with a correlating poorer prognosis [10].

Immune checkpoint inhibitors starting with the anti-CTLA-4 monoclonal antibody, Ipilimumab for melanoma $\left[{ }^{11}\right]$, have resulted in major advances in the treatment of multiple cancers including melanoma, non-small cell lung cancer, and renal carcinoma.

Immunotherapy with CTLA-4, PD-1 or PDL-1 antibodies increase overall survival and in a subpopulation cause durable response rates. Many immunotherapy clinical trials are currently underway for ovarian cancer [12]. A preliminary report of a phase $1 \mathrm{~b}$ trial with Avelumab, a PDL-1 antibody demonstrated reasonable clinical tolerability and a promising best overall response of $17.4 \%$ (4/23 pts) [13]. A phase II clinical trial with nivolumab, an anti-PD-1 antibody for patients with platinum resistant or recurrent ovarian cancer demonstrated an acceptable safety profile with an objective response rate of 15\% [14].

During the late 1980s and 1990s a number of phase one trials were completed using IP infusion of immune modifying agents, including, but not limited to IFN-a [15_21], IFN$\gamma\left[22{ }^{29}\right]$, IL-2 [30], monocytes [27, 31_33], and muramyl tripeptide phosphatidylethanolamine (MTP-PE) [31] for treatment of cancers involving organs in the peritoneal cavity. The large-scale production of cytokines and the production of therapeutic grade lymphocytes through counter-elutriation paved the way for infusion of the cytokines, lymphocytes, and cytokine stimulated lymphocytes for the treatment of malignancies of the peritoneal cavity. Studies focused on, but were not limited to, the treatment of ovarian cancer. There has been only one Phase 1 study of the combination of IFN- $\alpha$ and IFN- $\gamma$ administered intra-muscularly (IM), with one of nine patients showing a partial response[34]. The authors continued the therapy into a Phase 2 trial of IM IFN- $\alpha$ and IFN- $\gamma$ 
for the treatment of solid tumors $\left[{ }^{35}\right]$. The study had a $38 \%$ objective response. Interestingly, the authors state that no definitive synergistic effect was achieved. IFN-a has been combined with standard platin and taxane based chemotherapy with limited increases over standard of care. There have been no recent studies of intraperitoneal immunotherapy despite the success of intraperitoneal chemotherapy starting with the study by Alberts et al. in 1996[36]. Given the recent successes of immunotherapy in other malignancies, intraperitoneal immunotherapy combining both cell and cytokine therapy is a promising area for exploration.

\section{Interferons and the treatment of cancer}

Soon after the publication by Issacs and Lindemann that interferon blocked viral infection $\left[{ }^{37}\right]$, Paucker et al showed that IFN-a was capable of stopping the growth of malignant cell lines[38]. This observation of IFN mediated inhibition of cell growth was shown with IFN- $\gamma$ with human cells $\left[{ }^{29}\right]$ and in mice $\left[{ }^{39}\right]$. Human IFN- $\alpha 2$ is part of the Type 1 Interferon family that consisting of 12 active IFN-a proteins, 1 Interferon Beta, Interferon omega, Iinterferon kappa, interferon epsilon, and signals through the IFNAR1 and IFNAR2 receptors[40]. The binding of Type I IFNs to their the receptors results in the phosphorylation of STAT1 and STAT2 and subsequent trimer formation with IRF9 (Figure 1). The STAT1-STAT2-IRF9 complex forms a transcriptionally active complex called then IFN-stimulated gene factor 3 (ISGF3). The ISGF3 complex translocates to the nucleus and binds to conserved DNA sequences called IFN-stimulated response elements (ISRE). These events result in the transcription and translation of hundreds of interferon stimulated genes (ISGs). IFN- $\gamma$ is the only Type 2 interferon and forms a dimer that binds to dimers of IFNGR 1 and IFNGR 2 to form the IFN- $\gamma$ receptor complex. IFN- $\gamma$ 's interaction with its receptor results in the phosphorylation of STAT1. Phosphorylated STAT1 forms a dimer that translocates to the nucleus and binds conserved DNA sequences called IFN- $\gamma$ activated Sites (GAS) again resulting in the transcription and translation of hundreds of ISGs It has also been shown that IFN- $\gamma$ can result in STAT1 mediated gene transcription that is independent of phosphorylation, indicating complex regulation of IFN induced genes. Despite the potent anti-neoplastic properties of IFN- $\alpha$ and IFN- $\gamma$, there are a limited number of in vitro studies showing the combination provide an even more potent anti-neoplastic response $\left[{ }^{41}\right]$.

Early studies showed that both IFN- $\alpha$ and IFN- $\gamma$ inhibits tumor cell growth (cytostatic) by arresting cell division in G1, decreasing de novo RNA synthesis, decreased amino acid uptake, and decreased protein synthesis[42]. Later studies showed that the both IFN-a and IFN- $\gamma$ anti-proliferative activities were dependent on STAT1 $\left[{ }^{43}\right]$. While IFN-a induces STAT2 phosphorylation there is a body of that indicates that most of the antiproliferative activities of both IFNs are STAT1 dependent. However, in the context of melanoma, the capacity of IFN-a to induce tumor rejection in the mouse was shown to be independent of STAT1 signaling in the tumor itself[44]. The authors did show that IP IFN-a increased survival in a natural killer cell, STAT1 dependent, mechanism. Recently it was shown that increase in total STAT1 expression levels in ovarian cancer tumor biopsies is correlated with increased disease free survival[45]. IFNs regulate the expression of STAT1, indicating the presence of IFNs in the tumor microenvironment. This evidence is supported by the detection of CXCL10, an ISG, in the same biopsies. 
While the molecular mechanisms of IFNs anti-proliferative and cytotoxic are still being elucidated, some studies have shed light onto critical pathways. In 1998 Chin et al showed that IFN- $\gamma$ mediated cell growth arrest was STAT1 dependent induction of the cell cycle inhibitor p21 [ $\left.{ }^{46}\right]$. Later studies showed that interferon stimulated gene RIG-G (IFIT3) also controlled $\mathrm{p} 21$ and $\mathrm{p} 27$ function by blocking the negative regulator of $\mathrm{p} 21$ and $\mathrm{p} 27$, JAB 1 [47]. The same study also showed that RIG-G (IFIT3) blocked c-myc further arresting cell cycle. An important study using all-trans retinoic acid showed that dual phosphorylation of STAT1 resulted in regulation of c-myc, cyclins, and p27 to induce cell cycle arrest in U-937 cells[48]. While the study did not use IFNs, it highlights potential pathways of IFN-STAT1 mediated cell cycle regualtions. The ISG Interferon Regulatory Factor 1 has multiple roles in anti-proliferation and induction ocf anti-proliferative and pro-apoptotic genes such as the executioner Caspase 1, and the cell cycle regulator p21[49]. Interferon mediated induction of the ISG PKA which results in the activation of Caspase 8 and PARP, driving the initiation of the extrinsic apoptotic cell death pathway [50,51]. Other ISGs that have been shown to have a role in cancer cell death are the death ligands TRIAL and CD95L (FASL), and the secretion of pro-inflammatory chemokines (IP-10 and MIG) which recruit pro-inflammatory cytotoxic lymphocytes[40].

We have shown that while IFN- $a$ and IFN- $\gamma$ are capable of inhibiting cell growth or killing cancer cells, the combination creates a stronger killing effect $[52,53]$. We have expanded this observation to show that IFNs are potent killers of ovarian cancer cells lines, and there is synergism with the IFNs and the current standard of care of carboplatin and paclitaxel[54]. IFN- $a$ can also induce tumor cell apoptosis by stimulating the tumor cells to produce the cell death ligand TRAIL, which through an autocrine feedback loop, kills the tumor cells expressing the receptors for TRAIL (DR4/DR5)[55]. TRAIL signaling results in a Caspase 8 mediated cleavage of BID to tBID, followed by Bak dimerization, loss of mitochondrial membrane potential and release of apoptosis inducing factor which results in cell death in ovarian cancer cells (OVCAR3)[55].

In their landmark paper in 1998, Kaplan et al showed that IFN- $\gamma$ was a critical mediator of immune surveillance, tumor rejection, and increased time to tumor incidence in a spontaneous cancer mouse model using the carcinogen methylcholanthrene (MCA)[56]. At the time the authors hypothesized that IFN- $\gamma$ was exerting these antitumor properties through a mixture of innate and adaptive immune responses. These observations were followed by another seminal study by the same group using the MCA model and Type 1 IFN $\left[{ }^{57}\right]$. Using similar methods in their 1998 paper, Dunn et al showed that endogenous Type 1 IFN was necessary for rejection of MCA induced tumors. Using IFN alpha-receptor knockout mice, the authors show that the endogenous Type 1 IFN induced rejection that was dependent on IFNAR expression on cells of the hematopoetic system and not the tumor themselves. Using mice deficient in cells of the adaptive immune system, the authors showed that tumor rejection was dependent on innate immune cells [58]. Interestingly, a follow up study showed that Type 1 IFN rejection using the MCA model in immunodeficient mice was dependent on dendritic cell rejection of tumors [59]. However, other studies have shown that the activation of NK cells also increases tumor cell death in vitro and in vivo $[60,61]$. These observations highlight the complex nature of the immune response to cancers and warrant further studies. Further studies are needed to elucidate how exogenous IFNs can decrease or 
eliminate tumors in mouse models with established disease, and in vitro and in vivo evidence that IFNs can act directly on tumor cells.

In a series of experiments, Fleischmann showed that while Type 1 IFNs (IFN- $\alpha$ or IFN- $\beta$ ) were capable of killing tumor cells of murine and human origin that the addition of both cytokines to cell culture resulted in synergistic killing[62]. These experiments were supported by in vivo data showing that oral administration of IFN-a with IP administration of IFN- $\gamma$ resulted in increased life span in an IP model of melanoma $\left[{ }^{41}\right]$. Mouse bearing B16 melanoma cells were given saline, oral IFNa, IP IFN- $\gamma$, oral IFNa with IP IFN- $\gamma$, IP IFN- $a$, or oral IFN- $a$ and IP IFNa. Interestingly the investigators did not try the addition of IP IFNa and IP IFN- $\gamma$. While the single agent treatment groups showed some increased survival over controls, the greatest amount of survival was seen with the combination of oral IFN- $\alpha$ and IP IFN- $\gamma$. These data supported the in vitro findings and provided the rationale for the use of IFN- $\alpha$ and IFN- $\gamma$ in combination for the treatment of cancers involving the peritoneum.

IFN-a 2 is by the United States Food and Drug Administration for the treatment of Hairy Cell Leukemia, Chronic Myelogenous Leukemia, Malignant Melanoma, AIDS-related Kaposi's Sarcoma, and Follicular Lymphoma $\left.{ }^{40}\right]$. However, IFN-a has had limited efficacy in the clinic. The limited efficacy can be, in part, attributed to the off target effects, and significant side effects. The type 1 IFN receptor is on all cells in the human body, and no targeted therapy using IFNs for the treatment of cancer cells exists. The result of ubiquitous receptor expression is the need to give high concentrations of IFN-a resulting in even more severe side effects. Currently IFN- $\gamma$ is not licensed for the treatment of any malignancies. However, it is approved by the FDA to treat Chronic Granulomatous Disease and Osteopetrosis[40].

\section{Monocytes and macrophages}

Monocytes are a central component to the innate immune response to pathogens. Human monocytes are divided into three subsets based on the expression of CD14 and CD16[ $\left[{ }^{63}\right]$. Classical monocytes are defined as $\mathrm{CD} 14^{+} \mathrm{CD} 16^{-}$. Intermediate monocytes are defined by $\mathrm{CD} 14^{+} \mathrm{CD} 16^{+}$and non-classical monocytes are $\mathrm{CD} 14^{\mathrm{lo} /-} / \mathrm{CD} 16^{+}$. While there are only two subsets of monocytes in mouse, studies have shown that human classical monocytes are similar in transcriptional profile and function as murine classical monocytes $\left(\mathrm{GR} 1^{++}\right)$, while human non-classical monocytes are similar in transcriptional profile and function to (GR1 $\left.{ }^{-}\right)$ murine patrolling monocytes $\left[{ }^{64}, 65\right]$. No murine equivalent to the human intermediate population has been discovered.

Granger and Weiser were the first to show that macrophages were capable of killing neoplastic cells. Three independent research groups showed that murine macrophages, independent of alloreactivity were capable of killing tumor cells when cultured in vitro or in vivo with diverse pathogens or PAMPs[ $\left[66 \_68\right]$. The observation that macrophages were capable of non-specific killing of tumor cells was supported by in vitro studies that showed that the cytotoxicity was independent of the phagocytic activity of the macrophages, and that macrophages needed to be in the presence of the malignant cells to confer their cytotoxic 
action. It was further shown that immune mediators, independent of microbial stimuli, such as IFN- $\gamma$ could induce the cytotoxicity[69]. These observations were critical in showing that IFN was capable of inducing an innate immune response to cancer outside of its direct antiproliferative effects. Further studies by Hibbs showed that the major mechanism of action of macrophage-mediated killing of tumor cells was dependent on the release of nitric oxide (NO) radicals by the activated macrophages[69]. However, studies showed that unlike murine macrophages, human macrophages are weak producers of NO. Unfortunately this observation ended the possibility of using macrophages stimulated by IFN- $\gamma$ or microbial products for the treatment of human cancer from the perspective of harnessing NO mediated tumor cell death (Personal Communication DSG and Dr. Hibbs).

During inflammation in cancer monocytes migrate from the blood into affected tissue and differentiate into macrophages $\left[{ }^{70}\right]$. Depending on the tissue microenvironment the monocytes will differentiate into either pro-inflammatory M1 macrophages, or inhibitory M2 macrophages[71]. Within the tissue macrophages shape the local immune response through the detection of pathogen associated molecular patterns (PAMPs) and Danger Associated Molecular Patterns (DAMPs), and secrete multiple effector cytokines[72]. While M1 macrophages drive the infiltration of pro-inflammatory immune cells [ $\left.{ }^{73}\right], \mathrm{M} 2$ macrophages drive an anti-inflammatory response driven by a myriad of immunosuppressant lipids, proteins, and cells[74]. The complex dynamics of steady state maintenance of tissue macrophages by monocytes and changes associated with inflammation are currently being further defined.

While early evidence showed that IFNs were capable of enhancing the killing properties of monocytes/macrophages, there were no studies that analyzed if the cytotoxicity would be increased by the combination of IFN- $\alpha$, IFN- $\gamma$, and monocytes. In 2007 we showed that while IFNs were capable of inducing cytotoxicity in a number of cancer cell lines, the addition of monocytes to the culture significantly increased the cytotoxicity $\left[{ }^{53}\right]$. Using a intratumoral injection, mouse model with an human ovarian cancer cell line we showed that while there was no significant reduction in tumor size with IFNs or monocytes alone, there was significant decrease in tumor volume and complete response in some animals that received injection of IFNs and monocytes at the time of tumor initiating[55]. Importantly administration of IFNs and monocytes 15 days after the injection of tumor cells exhibited a similar response to Day 0 in both tumor volume and complete response. Animals that received injection of IFNs and monocytes 30 days after tumor injection had an increase in tumor volume compared to Day 0 and Day 15 treatment groups. However, there was still a significant difference in tumor volume between Day 30 treatment and the control group.

Histological analysis of the tumors showed infiltration of PECAM/CD68 positive cells in tumors from IFN and monocyte treatment groups, but not in controls. Of important note is that there were no CD68 positive cells in the monocyte treatment group, showing that even intratumoral injection of cells is not sufficient for the maturation of monocytes into macrophages. The presence of PECAM/CD68 positive cells indicated the presence of intratumoral activated macrophages. Using IHC we further showed that the cells expressed high levels of IL-12, CXCL10, and NOS2 indicating a proinflammatory, M1 phenotype. The 
cells were negative for inhibitory markers IL-10 and arginase. Together, these data indicate that IFN and monocytes in combination could be an effective treatment for ovarian cancer.

To expand on these studies we screened a number of high-grade serous ovarian epithelial cell lines in vitro for sensitivity to IFN and monocyte killing $\left[{ }^{54}\right]$. We found that while there was variation in the amount of killing across lines, there was statistically significant killing in all lines tested. Furthermore, the addition of carboplatin and paclitaxel increase the amount of synergistic killing. Further studies are needed to elucidate how the IFNs and monocytes are killing the cell lines. Earlier studies of monocytes treated with IFN-a showed that IFN-a induced the up-regulation of TRAIL, which resulted in the killing of target cells[75].

Much like other solid tumor metastatic cancers the immune landscape of the tumor in ovarian cancer has been correlated with patient outcome[ $\left.{ }^{76}, 77\right]$. Due to the recent success in using monoclonal antibodies that block checkpoint inhibitors, such as PD1, PD-L1, PD2, PD-L2 and CTLA-4, studies have analyzed the role of these ligands in the context of ovarian cancer.

The prognostic value of PD-L1 is contradictory, with PD-L1 expression initially being correlated with poorer prognosis $\left[{ }^{10}\right]$. However, data indicate that the presence of inhibitory cells and molecules is not de facto evidence of an immune suppressive environment. More recently, with improved immunohistochemistry assays and utilization of mRNA, PDL-1 and PD-1 expression has been associated with an increase in TILs, better disease outcome with better progression free survival (PFS) and even overall survival in patients with ovarian high grade serous carcinoma[78]. This has been shown consistently in other malignancies including breast cancer $\left[{ }^{79}, 80\right]$, mismatch repair- proficient colorectal cancer [81] and nonsmall cell lung cancer $\left[{ }^{82}, 83\right]$.

This paradoxical role of inhibitory receptors and their blockade in the treatment of cancer are currently being studied. PDL-1 up-regulation has been thought to be a marker for engaged $\mathrm{CD}^{+}$TILs suggesting a local cellular immune response and increased immune cell infiltrate. The mechanism for this is not clearly understood. PDL-1 with IL-2 initially was found to co-stimulate T-cell proliferation resulting in the secretion of IL-10, IFN- $\gamma$ and GCSF production $\left[{ }^{84}, 85\right]$. In turn, IFN- $\gamma$ induces the expression of PDL-1 on human tumors including ovarian cancer [8]. This can result in an increase in PD1 ${ }^{+} \mathrm{CD} 3^{+}$TILs [ ${ }^{78}$ ]. Both IFN- $\alpha$ and IFN- $\beta$ promote PDL-1 expression, negatively affecting T-cells and monocytes $[86,87]$.

\section{Combination therapies and the future}

Ovarian cancer is unique in that it is largely limited to the peritoneal cavity and the abdomen. Distant metastatic sites occur only very late in Stage 4 disease. Even with metastatic seeding of distant organs at the end stage of disease, most patients die from bowel obstructions. Despite anatomical restriction, most patients are diagnosed with a very high tumor burden within the peritoneal cavity. Tumor burden is so great that optimal surgical debulking is defined by centimeters. The accumulation of tumor cell rich ascites results in 
continual seeding of surfaces within the peritoneal cavity. Despite the high tumor burden, IP specific therapy has been shown to be effective. In optimally debulked patients, IP chemotherapy results in greater progression free survival than patients treated with the same chemotherapy IV.

It is now accepted that the immune system plays a critical role in cancer. While the immune system is critical for the surveillance and destruction of early cancers, it shapes the evolution of the cancer through an equilibrium stage where the immune system begins to be inhibited by the tumor, and escape, where the immune system is not only rendered ineffective in killing tumor cells, but is co-opted into creating a strong anti-inflammatory milieu that can blunt or stop ongoing immune responses. Based upon these observations checkpoint blockade inhibitors were proposed as a therapy to induce a strong, pro-inflammatory response to tumors.

Soon after the discovery of IFNs anti-viral properties, it was shown in vitro and in vivo that IFNs also possessed anti-neoplastic properties. While the mechanisms of action are still being elucidated it has been shown that IFNs act directly on tumor cells to arrest cell growth and induce cell death. More recent studies have shown that IFNs are also critical components of the immune systems response to tumors. Depending on cell type, time of expression, and duration of expression, IFNs have been shown to be anti-proliferative.

Within the context of ovarian cancer it seems that IFNs are potent anti-neoplastic agents. Studies of the effects of IFNs on human ovarian cancer cells were supported by Phase 1 trials of IP administration of IFNs into patients with ovarian cancer. Despite very promising early results (32\% complete response) these studies were not persued. It is not clear as to why these therapies were not followed up. It is possible that the introduction of more promising therapies, such as taxanes, turned focus away from IFNs.

While it has been shown that IFNs inhibit growth and kill ovarian cancer cells, it has been shown that the combination of IFN- $\alpha$ and IFN- $\gamma$ results in a synergistic killing of tumor cells. Further, while studies showed that IFN- $\alpha$ and monocytes or IFN- $\gamma$ and monocytes were cytotoxic, we showed that the combination of IFN-a, IFN- $\gamma$, and monocytes resulted in even greater cytotoxic effects. Our unpublished data indicate that the IFNs act on both the monocytes and the tumor cells to create synergistic killing. Published data shows that the use of IFNs and monocytes creates a highly pro-inflammatory environment that results in the transition of monocytes into pro-inflammatory M1 macrophages (Figure 2). Similar to checkpoint blockade inhibitors, IFNs and monocytes allow for the formation of a proinflammatory environment. Further studies are needed to see how the use of IFNs and monocytes influences the adaptive immune response to ovarian cancer. The anatomical restriction of ovarian cancer, and previous reports of efficacy in treating ovarian cancer with IFNs or monocytes, indicates that the combination of all three could create a promising autologous cell therapy for the treatment of ovarian cancer. Furthermore, our published data show that IFNs and monocytes combine synergistically with the standard chemotherapy agents carboplatin and paclitaxel. These data indicate the need for future studies using combination therapy with other immune-modifying treatments such as blockade inhibitors, SMAC mimetics, and recombinant cytokine immunotoxins. 


\section{Acknowledgments}

We would like to dedicate this review to the memory of Dr. Sam Baron. This work is supported by the NIH intramural research programs of the NIAID and the NCI.

\section{Biographies}

Daniel S. Green

Dr. Green received his BS in History from Willamette University. He completed his Ph.D at Boston University School of Medicine, in the laboratory of Dr. William Cruikshank, studying the role of the cytokine IL-16 in human T cell migration and signaling to lymph node homing cues. Dr. Green did a brief post-doctoral fellowship in the laboratory of Dr. Peter Polgar at Boston University School of Medicine, working on translating small peptide modifiers of endothelin signaling for the treatment of pulmonary arterial hypertension into small animal models. Currently Dr. Green is a post-doctoral fellow in the laboratory of Dr. Kathryn Zoon, studying the roles of interferons and monocytes in cancer, with a focus on translational medicine.

Ana T. Nunes

Dr. Nunes completed her MD and $\mathrm{PhD}$ at the University of Rochester in 2012 and is currently an Oncology Clinical Fellow at the NCI/NIH. Her graduate training was in physiology under the guidance of Mark Noble, examining systemic chemotherapeutic agents and the effects on differentiation and proliferation in the neural and oligodendrocyte progenitor cells in a mouse model. She completed internal medicine residency training in internal medicine at Scripps Green in La Jolla, CA. She was a member of the institutional review board during her time at Scripps and has conducted quality improvement studies on the consent process for neonates enrolled on clinical trials, as well as code status discussions on patients admitted to the hospital. Her current research interests include immunotherapy early-phase clinical trials with a focus in ovarian cancer under the guidance of Dr. Christina Annunziata.

\section{Christina M. Annunziata}

Dr. Annunziata is a graduate of Georgetown University Medical School where she also completed graduate school and residency training in internal medicine. She came to NCI for medical oncology training in the Medical Oncology Branch. Dr. Annunziata joined the laboratory of Dr. Louis Staudt in the Metabolism Branch to investigate NF-kappaB signaling in multiple myeloma. She returned to the Medical Oncology Branch to extend her study of these molecular pathways in the ovarian cancer model, and she maintains her clinical focus in the translational clinical studies of ovarian cancer. Dr. Annunziata now directs clinical operations for the Women's Malignancies Branch. Dr. Annunziata holds board certification for the practice of medical oncology. Dr. Annunziata is a participating member in the Gynecologic Oncology Group, the American Association for Cancer Research, the American Society for Clinical Oncology, and the Society of Gynecologic Oncology. She 
serves as course director for the Women's Malignancies Lecture Series in the Women's Malignancies Branch, and Associate Editor for the international journal, BMC Cancer.

Kathryn C. Zoon

Dr. Zoon obtained her B.S. cum laude and her Ph.D. in biochemistry from The Johns Hopkins University. Her research focuses on the structure and function of human IFNs and their anti-viral and anti-proliferative properties. She is an associate editor of the Journal of Interferon Research and author or co-author of more than 100 publications. She was past president of the International Society for Interferon and Cytokine Research (2000-2001), served on the board of directors for the Foundation for Advanced Education in the Sciences (FAES) and the International Association of Biologicals, and was the first vice president of FAES. Prior to joining NIAID in June 2004, Dr. Zoon was principal deputy director of the Center for Cancer Research at the National Cancer Institute, director of the Center for Biologics Evaluation and Research at the Food and Drug Administration, and a member of the National Institutes of Health Scientific Directors. She has received numerous awards and is a member of the Institute of Medicine.

\author{
Abbreviations \\ $($ IFN- $a)$ \\ $(\mathrm{IFN}-\gamma)$ \\ (TIL) \\ (TRAIL) \\ (IP) \\ Interferon Alpha \\ Interferon Gamma \\ Tumor Infiltrating Lyphocyte \\ TNF-related apoptosis-inducing ligand \\ Intraperitoneal
}

\title{
References
}

1. Jemal A, Siegel R, Xu J, Ward E. Cancer statistics, 2010. CA Cancer J Clin. 2010; 60:277-300. [PubMed: 20610543]

2. Ledermann JA, Raja FA, Fotopoulou C, Gonzalez-Martin A, Colombo N, Sessa C, et al. Newly diagnosed and relapsed epithelial ovarian carcinoma: ESMO Clinical Practice Guidelines for diagnosis, treatment and follow-up. Ann Oncol. 2013; 24(Suppl 6):vi24-32. [PubMed: 24078660]

3. Kooi S, Zhang HZ, Patenia R, Edwards CL, Platsoucas CD, Freedman RS. HLA class I expression on human ovarian carcinoma cells correlates with T-cell infiltration in vivo and T-cell expansion in vitro in low concentrations of recombinant interleukin-2. Cellular immunology. 1996; 174:116-28. [PubMed: 8954611]

4. Dadmarz RD, Ordoubadi A, Mixon A, Thompson CO, Barracchini KC, Hijazi YM, et al. Tumorinfiltrating lymphocytes from human ovarian cancer patients recognize autologous tumor in an MHC class II-restricted fashion. The cancer journal from Scientific American. 1996; 2:263-72. [PubMed: 9166543]

5. Freedman RS, Tomasovic B, Templin S, Atkinson EN, Kudelka A, Edwards CL, et al. Large-scale expansion in interleukin-2 of tumor-infiltrating lymphocytes from patients with ovarian carcinoma for adoptive immunotherapy. Journal of immunological methods. 1994; 167:145-60. [PubMed: 8308273]

6. Santin AD, Hermonat PL, Ravaggi A, Bellone S, Roman JJ, Smith CV, et al. Phenotypic and functional analysis of tumor-infiltrating lymphocytes compared with tumor-associated lymphocytes 
from ascitic fluid and peripheral blood lymphocytes in patients with advanced ovarian cancer. Gynecologic and obstetric investigation. 2001; 51:254-61. [PubMed: 11408737]

7. Zhang L, Conejo-Garcia JR, Katsaros D, Gimotty PA, Massobrio M, Regnani G, et al. Intratumoral T Cells, Recurrence, and Survival in Epithelial Ovarian Cancer. New England Journal of Medicine. 2003; 348:203-13. [PubMed: 12529460]

8. Dong H, Strome SE, Salomao DR, Tamura H, Hirano F, Flies DB, et al. Tumor-associated B7-H1 promotes T-cell apoptosis: a potential mechanism of immune evasion. Nature medicine. 2002; 8:793-800.

9. Abiko K, Mandai M, Hamanishi J, Yoshioka Y, Matsumura N, Baba T, et al. PD-L1 on tumor cells is induced in ascites and promotes peritoneal dissemination of ovarian cancer through CTL dysfunction. Clinical cancer research: an official journal of the American Association for Cancer Research. 2013; 19:1363-74. [PubMed: 23340297]

10. Hamanishi J, Mandai M, Iwasaki M, Okazaki T, Tanaka Y, Yamaguchi K, et al. Programmed cell death 1 ligand 1 and tumor-infiltrating CD8+ T lymphocytes are prognostic factors of human ovarian cancer. Proceedings of the National Academy of Sciences of the United States of America. 2007; 104:3360-5. [PubMed: 17360651]

11. Hodi FS, O’Day SJ, McDermott DF, Weber RW, Sosman JA, Haanen JB, et al. Improved survival with ipilimumab in patients with metastatic melanoma. The New England journal of medicine. 2010; 363:711-23. [PubMed: 20525992]

12. De Felice F, Marchetti C, Palaia I, Musio D, Muzii L, Tombolini V, et al. Immunotherapy of Ovarian Cancer: The Role of Checkpoint Inhibitors. Journal of immunology research. 2015; 2015:191832. [PubMed: 26236750]

13. Disis MLP MR, Pant S, Nfante JR, Lockhart AC, Kelly K, Beck JT, Gordon MS, Weiss GJ, Ejadi S, Taylor MH, von Heydebreck M, Chin KM, Cuillerot J, Gulley JL. Avelumab (MSB0010718C), an anti-PD-L1 antibody, in patients with previously treated, recurrent or refractory ovarian cancer: A phase Ib, open-label expansion trial. Journal of clinical oncology: official journal of the American Society of Clinical Oncology. 2015; 33(suppl) abstr 5509.

14. Hamanishi J, Mandai M, Ikeda T, Minami M, Kawaguchi A, Murayama T, et al. Safety and Antitumor Activity of Anti-PD-1 Antibody, Nivolumab, in Patients With Platinum-Resistant Ovarian Cancer. Journal of clinical oncology: official journal of the American Society of Clinical Oncology. 2015; 33:4015-22. [PubMed: 26351349]

15. Bezwoda WR, Seymour L, Dansey R. Intraperitoneal recombinant interferon-alpha $2 b$ for recurrent malignant ascites due to ovarian cancer. Cancer. 1989; 64:1029-33. [PubMed: 2758381]

16. Ferrari E, Maffeo DA, Graziano R, Gallo MS, Pignata S, De Rosa L, et al. Intraperitoneal chemotherapy with carboplatin and recombinant interferon alpha in ovarian cancer. Eur J Gynaecol Oncol. 1994; 15:437-42. [PubMed: 7875158]

17. Iaffaioli RV, Frasci G, Facchini G, Pagliarulo C, Pacelli R, Scala S, et al. Alpha 2b interferon (IFN) by intraperitoneal administration via temporary catheter in ovarian cancer. Preliminary data. Eur J Gynaecol Oncol. 1991; 12:69-75. [PubMed: 2050163]

18. Lichtenstein A, Spina C, Berek JS, Jung T, Zighelboim J. Intraperitoneal administration of human recombinant interferon-alpha in patients with ovarian cancer: effects on lymphocyte phenotype and cytotoxicity. Cancer Res. 1988; 48:5853-9. [PubMed: 3167841]

19. Moore DH, Valea F, Walton LA, Soper J, Clarke-Pearson D, Fowler WC Jr. A phase I study of intraperitoneal interferon-alpha $2 \mathrm{~b}$ and intravenous cis-platinum plus cyclophosphamide chemotherapy in patients with untreated stage III epithelial ovarian cancer: a Gynecologic Oncology Group pilot study. Gynecol Oncol. 1995; 59:267-72. [PubMed: 7590485]

20. Repetto L, Chiara S, Guido T, Bruzzone M, Oliva C, Ragni N, et al. Intraperitoneal chemotherapy with carboplatin and interferon alpha in the treatment of relapsed ovarian cancer: a pilot study. Anticancer Res. 1991; 11:1641-3. [PubMed: 1746921]

21. Schuller J, Czejka MJ, Schernthaner G, Wirth M, Bosse C, Jager W, et al. Pharmacokinetic aspects of interferon alfa-2b after intrahepatic or intraperitoneal administration. Semin Oncol. 1992; 19:98-104. [PubMed: 1557662]

22. Allavena P, Peccatori F, Maggioni D, Erroi A, Sironi M, Colombo N, et al. Intraperitoneal recombinant gamma-interferon in patients with recurrent ascitic ovarian carcinoma: modulation of 
cytotoxicity and cytokine production in tumor-associated effectors and of major histocompatibility antigen expression on tumor cells. Cancer Res. 1990; 50:7318-23. [PubMed: 2121337]

23. Colombo N, Peccatori F, Paganin C, Bini S, Brandely M, Mangioni C, et al. Anti-tumor and immunomodulatory activity of intraperitoneal IFN-gamma in ovarian carcinoma patients with minimal residual tumor after chemotherapy. Int J Cancer. 1992; 51:42-6. [PubMed: 1563843]

24. D'Acquisto R, Markman M, Hakes T, Rubin S, Hoskins W, Lewis JL Jr. A phase I trial of intraperitoneal recombinant gamma-interferon in advanced ovarian carcinoma. J Clin Oncol. 1988; 6:689-95. [PubMed: 3128649]

25. Malik ST, Knowles RG, East N, Lando D, Stamp G, Balkwill FR. Antitumor activity of gammainterferon in ascitic and solid tumor models of human ovarian cancer. Cancer Res. 1991; 51:66439. [PubMed: 1742738]

26. Pujade-Lauraine E, Guastalla JP, Colombo N, Devillier P, Francois E, Fumoleau P, et al. Intraperitoneal recombinant interferon gamma in ovarian cancer patients with residual disease at second-look laparotomy. J Clin Oncol. 1996; 14:343-50. [PubMed: 8636742]

27. Stevenson HC, Keenan AM, Woodhouse C, Ottow RT, Miller P, Steller EP, et al. Fate of gammainterferon-activated killer blood monocytes adoptively transferred into the abdominal cavity of patients with peritoneal carcinomatosis. Cancer Res. 1987; 47:6100-3. [PubMed: 3117363]

28. Andreesen R, Hennemann B, Krause SW. Adoptive immunotherapy of cancer using monocytederived macrophages: rationale, current status, and perspectives. J Leukoc Biol. 1998; 64:419-26. [PubMed: 9766621]

29. Green JA, Cooperband SR, Rutstein JA, Kibrick S. Inhibition of target cell proliferation by supernatants from cultures of human peripheral lymphocytes. J Immunol. 1970; 105:48-54. [PubMed: 5425353]

30. Freedman RS, Edwards CL, Kavanagh JJ, Kudelka AP, Katz RL, Carrasco CH, et al. Intraperitoneal adoptive immunotherapy of ovarian carcinoma with tumor-infiltrating lymphocytes and low-dose recombinant interleukin-2: a pilot trial. Journal of immunotherapy with emphasis on tumor immunology: official journal of the Society for Biological Therapy. 1994; 16:198-210.

31. Faradji A, Bohbot A, Frost H, Schmitt-Goguel M, Siffert JC, Dufour P, et al. Phase I study of liposomal MTP-PE-activated autologous monocytes administered intraperitoneally to patients with peritoneal carcinomatosis. J Clin Oncol. 1991; 9:1251-60. [PubMed: 2045866]

32. Faradji A, Bohbot A, Schmitt-Goguel M, Dumont S, Eischen A, Wiesel ML, et al. Apheresiselutriation program for adoptive immunotherapy with autologous activated monocytes in cancer patients. Int J Artif Organs. 1991; 14:304-12. [PubMed: 1864656]

33. Faradji A, Bohbot A, Schmitt-Goguel M, Siffert JC, Dumont S, Wiesel ML, et al. Large scale isolation of human blood monocytes by continuous flow centrifugation leukapheresis and counterflow centrifugation elutriation for adoptive cellular immunotherapy in cancer patients. $\mathrm{J}$ Immunol Methods. 1994; 174:297-309. [PubMed: 8083534]

34. Kurzrock R, Rosenblum MG, Quesada JR, Sherwin SA, Itri LM, Gutterman JU. Phase I study of a combination of recombinant interferon-alpha and recombinant interferon-gamma in cancer patients. J Clin Oncol. 1986; 4:1677-83. [PubMed: 3095504]

35. Quesada JR, Evans L, Saks SR, Gutterman JU. Recombinant interferon alpha and gamma in combination as treatment for metastatic renal cell carcinoma. J Biol Response Mod. 1988; 7:2349. [PubMed: 3134511]

36. Alberts DS, Liu PY, Hannigan EV, O'Toole R, Williams SD, Young JA, et al. Intraperitoneal cisplatin plus intravenous cyclophosphamide versus intravenous cisplatin plus intravenous cyclophosphamide for stage III ovarian cancer. N Engl J Med. 1996; 335:1950-5. [PubMed: 8960474]

37. Isaacs A, Lindenmann J. Virus interference. I. The interferon. Proc R Soc Lond B Biol Sci. 1957; 147:258-67. [PubMed: 13465720]

38. Paucker K, Cantell K, Henle W. Quantitative studies on viral interference in suspended L cells. III. Effect of interfering viruses and interferon on the growth rate of cells. Virology. 1962; 17:324-34. [PubMed: 14484446] 
39. Salvin SB, Youngner JS, Nishio J, Neta R. Tumor suppression by a lymphokine released into the circulation of mice with delayed hypersensitivity. J Natl Cancer Inst. 1975; 55:1233-6. [PubMed: 1206752]

40. Bekisz J, Sato Y, Johnson C, Husain SR, Puri RK, Zoon KC. Immunomodulatory effects of interferons in malignancies. J Interferon Cytokine Res. 2013; 33:154-61. [PubMed: 23570381]

41. Fleischmann WR Jr, Masoor J, Wu TY, Fleischmann CM. Orally administered IFN-alpha acts alone and in synergistic combination with intraperitoneally administered IFN-gamma to exert an antitumor effect against B16 melanoma in mice. J Interferon Cytokine Res. 1998; 18:17-20. [PubMed: 9475662]

42. II WES. The Interferon System. Springer-Verlag; Wien: 1979.

43. Bromberg JF, Horvath CM, Wen Z, Schreiber RD, Darnell JE Jr. Transcriptionally active Stat1 is required for the antiproliferative effects of both interferon alpha and interferon gamma. Proc Natl Acad Sci U S A. 1996; 93:7673-8. [PubMed: 8755534]

44. Lesinski GB, Anghelina M, Zimmerer J, Bakalakos T, Badgwell B, Parihar R, et al. The antitumor effects of IFN-alpha are abrogated in a STAT1-deficient mouse. J Clin Invest. 2003; 112:170-80. [PubMed: 12865406]

45. Koti M, Siu A, Clement I, Bidarimath M, Turashvili G, Edwards A, et al. A distinct pre-existing inflammatory tumour microenvironment is associated with chemotherapy resistance in high-grade serous epithelial ovarian cancer. Br J Cancer. 2015; 113:1746. [PubMed: 26695556]

46. Chin YE, Kitagawa M, Su WC, You ZH, Iwamoto Y, Fu XY. Cell growth arrest and induction of cyclin-dependent kinase inhibitor p21 WAF1/CIP1 mediated by STAT1. Science. 1996; 272:71922. [PubMed: 8614832]

47. Xiao S, Li D, Zhu HQ, Song MG, Pan XR, Jia PM, et al. RIG-G as a key mediator of the antiproliferative activity of interferon-related pathways through enhancing p21 and p27 proteins. Proc Natl Acad Sci U S A. 2006; 103:16448-53. [PubMed: 17050680]

48. Dimberg A, Karlberg I, Nilsson K, Oberg F. Ser727/Tyr701-phosphorylated Stat1 is required for the regulation of c-Myc, cyclins, and p27Kip1 associated with ATRA-induced G0/G1 arrest of U-937 cells. Blood. 2003; 102:254-61. [PubMed: 12637327]

49. Romeo G, Fiorucci G, Chiantore MV, Percario ZA, Vannucchi S, Affabris E. IRF-1 as a negative regulator of cell proliferation. J Interferon Cytokine Res. 2002; 22:39-47. [PubMed: 11846974]

50. Lee SB, Rodriguez D, Rodriguez JR, Esteban M. The apoptosis pathway triggered by the interferon-induced protein kinase PKR requires the third basic domain, initiates upstream of Bcl-2, and involves ICE-like proteases. Virology. 1997; 231:81-8. [PubMed: 9143305]

51. Gil J, Esteban M. The interferon-induced protein kinase (PKR), triggers apoptosis through FADDmediated activation of caspase 8 in a manner independent of Fas and TNF-alpha receptors. Oncogene. 2000; 19:3665-74. [PubMed: 10951573]

52. Baron S, Finbloom J, Horowitz J, Bekisz J, Morrow A, Zhao T, et al. Near eradication of clinically relevant concentrations of human tumor cells by interferon-activated monocytes in vitro. $\mathrm{J}$ Interferon Cytokine Res. 2011; 31:569-73. [PubMed: 21323569]

53. Baron S, Hernandez J, Bekisz J, Poast J, Goldman N, Clouse K, et al. Clinical model: interferons activate human monocytes to an eradicative tumor cell level in vitro. J Interferon Cytokine Res. 2007; 27:157-63. [PubMed: 17316143]

54. Johnson CL, Green DS, Zoon KC. Human monocytes in the presence of interferons alpha2a and gamma are potent killers of serous ovarian cancer cell lines in combination with paclitaxel and carboplatin. J Interferon Cytokine Res. 2015; 35:55-62. [PubMed: 25068849]

55. Nakashima H, Miyake K, Clark CR, Bekisz J, Finbloom J, Husain SR, et al. Potent antitumor effects of combination therapy with IFNs and monocytes in mouse models of established human ovarian and melanoma tumors. Cancer Immunol Immunother. 2012; 61:1081-92. [PubMed: 22159517]

56. Kaplan DH, Shankaran V, Dighe AS, Stockert E, Aguet M, Old LJ, et al. Demonstration of an interferon gamma-dependent tumor surveillance system in immunocompetent mice. Proc Natl Acad Sci U S A. 1998; 95:7556-61. [PubMed: 9636188]

57. Dunn GP, Bruce AT, Sheehan KC, Shankaran V, Uppaluri R, Bui JD, et al. A critical function for type I interferons in cancer immunoediting. Nat Immunol. 2005; 6:722-9. [PubMed: 15951814] 
58. Bui JD, Schreiber RD. Cancer immunosurveillance, immunoediting and inflammation: independent or interdependent processes? Curr Opin Immunol. 2007; 19:203-8. [PubMed: 17292599]

59. Diamond MS, Kinder M, Matsushita H, Mashayekhi M, Dunn GP, Archambault JM, et al. Type I interferon is selectively required by dendritic cells for immune rejection of tumors. J Exp Med. 2011; 208:1989-2003. [PubMed: 21930769]

60. Trinchieri G, Santoli D. Anti-viral activity induced by culturing lymphocytes with tumor-derived or virus-transformed cells. Enhancement of human natural killer cell activity by interferon and antagonistic inhibition of susceptibility of target cells to lysis. J Exp Med. 1978; 147:1314-33. [PubMed: 650156]

61. Lee CK, Rao DT, Gertner R, Gimeno R, Frey AB, Levy DE. Distinct requirements for IFNs and STAT1 in NK cell function. J Immunol. 2000; 165:3571-7. [PubMed: 11034357]

62. Fleischmann WR Jr, Schwarz LA, Fleischmann CM. Requirement for IFN gamma in potentiation of interferon's antiviral and anticellular activities: identity of mouse and human systems. J Interferon Res. 1984; 4:265-74. [PubMed: 6431021]

63. Ziegler-Heitbrock L. Blood Monocytes and Their Subsets: Established Features and Open Questions. Front Immunol. 2015; 6:423. [PubMed: 26347746]

64. Cros J, Cagnard N, Woollard K, Patey N, Zhang SY, Senechal B, et al. Human CD14dim monocytes patrol and sense nucleic acids and viruses via TLR7 and TLR8 receptors. Immunity. 2010; 33:375-86. [PubMed: 20832340]

65. Ingersoll MA, Spanbroek R, Lottaz C, Gautier EL, Frankenberger M, Hoffmann R, et al. Comparison of gene expression profiles between human and mouse monocyte subsets. Blood. 2010; 115:e10-9. [PubMed: 19965649]

66. Alexander P, Evans R. Endotoxin and double stranded RNA render macrophages cytotoxic. Nat New Biol. 1971; 232:76-8. [PubMed: 5285341]

67. Keller R, Jones VE. Role of activated macrophages and antibody in inhibition and enhancement of tumour growth in rats. Lancet. 1971; 2:847-9. [PubMed: 4106873]

68. Hibbs JB Jr, Lambert LH Jr, Remington JS. Possible role of macrophage mediated nonspecific cytotoxicity in tumour resistance. Nat New Biol. 1972; 235:48-50. [PubMed: 4109405]

69. Hibbs JB Jr. Infection and nitric oxide. J Infect Dis. 2002; 185(Suppl 1):S9-17. [PubMed: 11865435]

70. Qian BZ, Li J, Zhang H, Kitamura T, Zhang J, Campion LR, et al. CCL2 recruits inflammatory monocytes to facilitate breast-tumour metastasis. Nature. 2011; 475:222-5. [PubMed: 21654748]

71. Italiani P, Boraschi D. From Monocytes to M1/M2 Macrophages: Phenotypical vs. Functional Differentiation. Front Immunol. 2014; 5:514. [PubMed: 25368618]

72. Edwards JP, Zhang X, Frauwirth KA, Mosser DM. Biochemical and functional characterization of three activated macrophage populations. J Leukoc Biol. 2006; 80:1298-307. [PubMed: 16905575]

73. Sica A, Mantovani A. Macrophage plasticity and polarization: in vivo veritas. J Clin Invest. 2012; 122:787-95. [PubMed: 22378047]

74. Ruffell B, Affara NI, Coussens LM. Differential macrophage programming in the tumor microenvironment. Trends Immunol. 2012; 33:119-26. [PubMed: 22277903]

75. Miyake K, Bekisz J, Zhao T, Clark CR, Zoon KC. Apoptosis-inducing factor (AIF) is targeted in IFN-alpha2a-induced Bid-mediated apoptosis through Bak activation in ovarian cancer cells. Biochim Biophys Acta. 2012; 1823:1378-88. [PubMed: 22683989]

76. Nelson BH. The impact of T-cell immunity on ovarian cancer outcomes. Immunol Rev. 2008; 222:101-16. [PubMed: 18363996]

77. Cancer Genome Atlas Research N. Integrated genomic analyses of ovarian carcinoma. Nature. 2011; 474:609-15. [PubMed: 21720365]

78. Darb-Esfahani S, Kunze CA, Kulbe H, Sehouli J, Wienert S, Lindner J, et al. Prognostic impact of programmed cell death-1 (PD-1) and PD-ligand 1 (PD-L1) expression in cancer cells and tumorinfiltrating lymphocytes in ovarian high grade serous carcinoma. Oncotarget. 2015

79. Schalper KA, Velcheti V, Carvajal D, Wimberly H, Brown J, Pusztai L, et al. In situ tumor PD-L1 mRNA expression is associated with increased TILs and better outcome in breast carcinomas. 
Clinical cancer research: an official journal of the American Association for Cancer Research. 2014; 20:2773-82. [PubMed: 24647569]

80. Sabatier R, Finetti P, Mamessier E, Adelaide J, Chaffanet M, Ali HR, et al. Prognostic and predictive value of PDL1 expression in breast cancer. Oncotarget. 2015; 6:5449-64. [PubMed: 25669979]

81. Droeser RA, Hirt C, Viehl CT, Frey DM, Nebiker C, Huber X, et al. Clinical impact of programmed cell death ligand 1 expression in colorectal cancer. European journal of cancer (Oxford, England: 1990). 2013; 49:2233-42.

82. Velcheti V, Schalper KA, Carvajal DE, Anagnostou VK, Syrigos KN, Sznol M, et al. Programmed death ligand-1 expression in non-small cell lung cancer. Laboratory investigation; a journal of technical methods and pathology. 2014; 94:107-16.

83. Schmidt LH, Kummel A, Gorlich D, Mohr M, Brockling S, Mikesch JH, et al. PD-1 and PD-L1 Expression in NSCLC Indicate a Favorable Prognosis in Defined Subgroups. PloS one. 2015; 10:e0136023. [PubMed: 26313362]

84. Dong H, Zhu G, Tamada K, Chen L. B7-H1, a third member of the B7 family, co-stimulates T-cell proliferation and interleukin-10 secretion. Nature medicine. 1999; 5:1365-9.

85. Tamura H, Dong H, Zhu G, Sica GL, Flies DB, Tamada K, et al. B7-H1 costimulation preferentially enhances CD28-independent T-helper cell function. Blood. 2001; 97:1809-16. [PubMed: 11238124]

86. Schreiner B, Mitsdoerffer M, Kieseier BC, Chen L, Hartung H-P, Weller M, et al. Interferon- $\beta$ enhances monocyte and dendritic cell expression of B7-H1 (PD-L1), a strong inhibitor of autologous T-cell activation: relevance for the immune modulatory effect in multiple sclerosis. Journal of Neuroimmunology. 155:172-82. [PubMed: 15342209]

87. Boasso A, Hardy AW, Landay AL, Martinson JL, Anderson SA, Dolan MJ, et al. PDL-1 upregulation on monocytes and T cells by HIV via type I interferon: restricted expression of type I interferon receptor by CCR5-expressing leukocytes. Clinical immunology (Orlando, Fla). 2008; 129:132-44. 


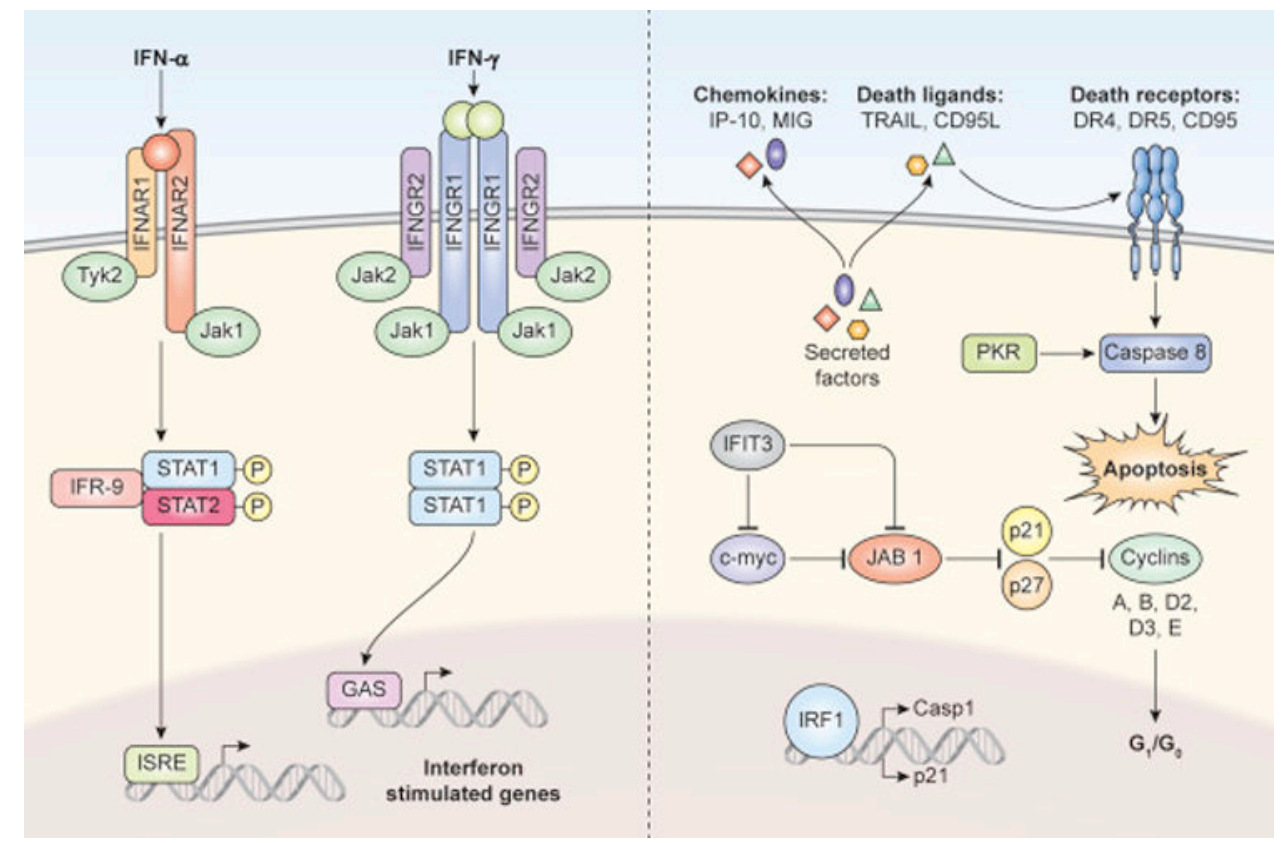

Figure 1.

Interferon Signaling and regulation of anti-proliferative and cytotoxic proteins. IFNa and IFNg signal through the Interferon Alpha Receptor and Interferon Gamma Receptor respectively, inducing JAK/STAT signaling. JAK/STAT signaling results in the transcriptional activation of interferon stimulated genes. ISGs can be categorized as antiproliferative (IFIT3, IRF1, p21), cytotoxic (PKR, Caspase 1, TRAIL, CD95L) and immunomodulatory (IP-10, MIG). Art by Ethan Tyler of the NIH Medical Arts Branch. 


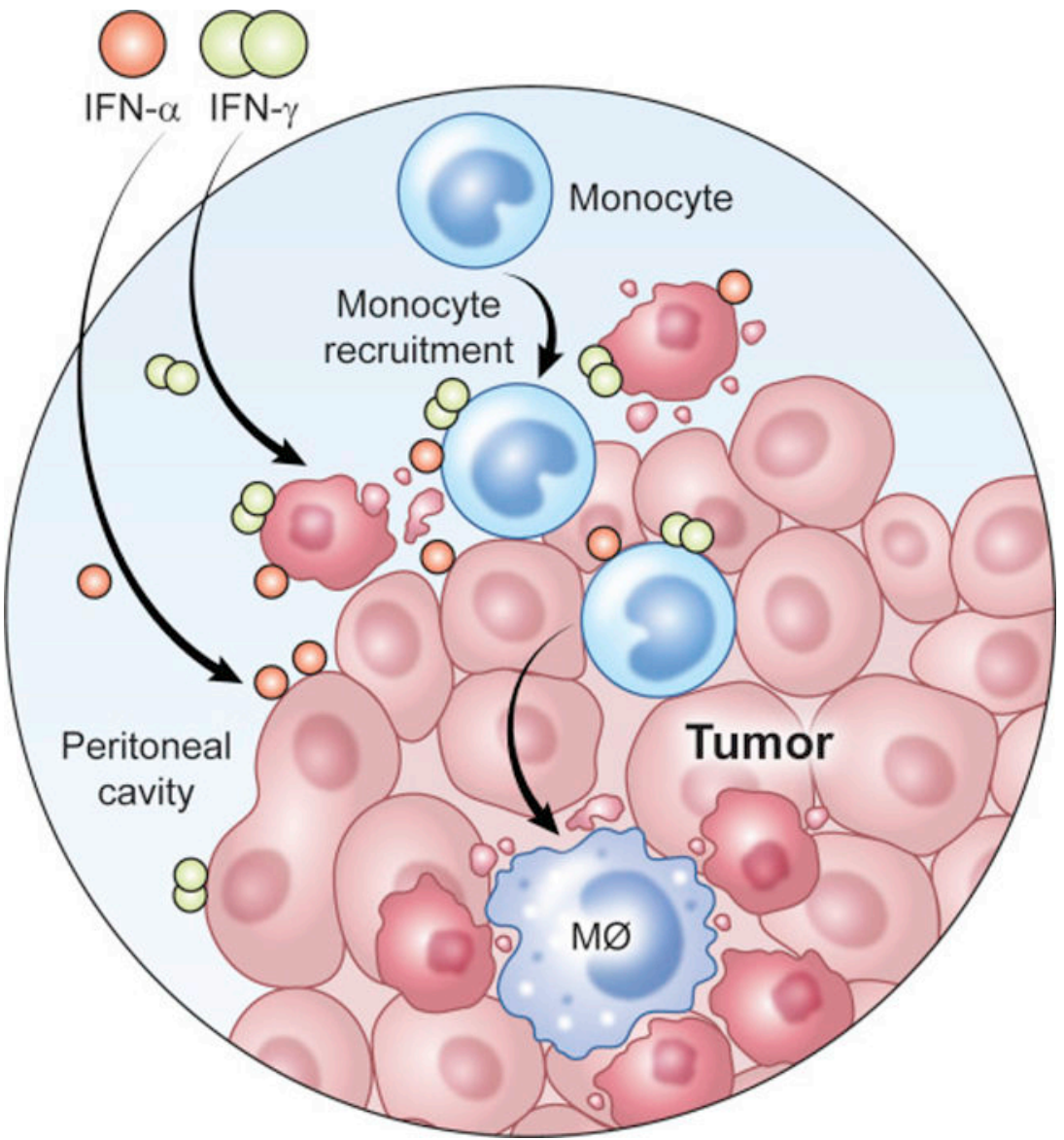

Figure 2.

Proposed use of interferons and monocytes for the treatment of ovarian cancer. IFNs and monocytes would be injected into the peritoneal cavity of patients with metastatic ovarian cancer. Based on animal models, the monocytes would mature into M1 macrophages resulting in killing of ovarian cancer cells. Both laboratory and clinical data have shown that IFNs also act directly on ovarian cancer cells resulting in apoptotic cell death. Art by Ethan Tyler of the NIH Medical Arts Branch. 